PROCESSO LABORATORIAL PARA O REAPROVEITAMENTO DO MOLDE CERÂMICO PROVENIENTE DA MICROFUSÃO

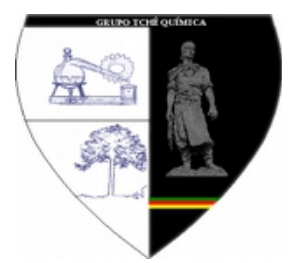

\title{
LABORATORY PROCESS FOR THE RECLAIMING OF THE CERAMICS MOLD FROM THE INVESTMENT CASTING
}

\author{
DE BONI, Luis Alcides Brandini ${ }^{1 *}$; CRIVELETTO, Vagner ${ }^{2}$; CAMANA, Marcos ${ }^{3}$; \\ 1,2,3 Micromazza - PMP Ltda Rod. RSC 470 Km 168. Vila Flores - RS, Brasil \\ (fone: +55 542345 4356) \\ ${ }^{*}$ Autor correspondente \\ e-mail: labdeboni@gmail.com
}

Received 12 December 2012; received in revised form 30 January 2013; accepted 10 February 2013

\section{RESUMO}

A microfusão é um processo utilizado para a produção de peças com variações ou tolerâncias dimensionais restritas, de tal forma que após a fundição as peças necessitam de pouco acabamento. $O$ presente trabalho descreve um experimento realizado visando o reaproveitamento de parte dos subprodutos provenientes do processo de microfusão. Cerca de $4 \mathrm{~kg}$ de casca cerâmica passaram por um processo de trituramento, separação magnética de metais e classificação por peneiras, ao invés de serem destinados ao aterro sanitário. O material foi separado em peneiras de diferentes granulometrias e agrupado em dois conjuntos, um para o material de maior granulometria e outro para o de menor granulometria. Posteriormente este material foi utilizado na produção de um molde cerâmico utilizado no processo de microfusão, substituindo a respectiva matéria-prima virgem. A casca cerâmica do cacho produzido através desta técnica, suportou todas as etapas de sua montagem, incluindo o vazamento do aço (WCB) sem quebrar ou trincar. O reaproveitamento da matéria-prima, neste experimento, atingiu cerca de $80 \%$ em peso dos $4 \mathrm{~kg}$ obtidos originalmente.

Palavras-chave: Microfusão, reciclagem de casca cerâmica, redução de resíduos.

\begin{abstract}
Investment casting is a process used to produce parts with restricted dimensional tolerances so that after casting the parts require little or no finishing. This paper describes an experiment conducted to the reuse of by-products from the process of investment casting. Around $4 \mathrm{~kg}$ of ceramic shell went through a process of crushing, magnetic separation of metals and screen classification, instead of being destined to the landfill. The material was separated on sieves of different diameters and grouped in two sets, one for the material of larger particle size and another for smaller particle sizes. Subsequently this material was used to produce a ceramic mold used in investment casting process, replacing the corresponding virgin raw material. The ceramic shell of the bunch produced by this technique, endured all stages of assembly, including the casting of steel (WCB) without break or crack. The reuse of raw materials in this experiment reached about $80 \%$ by weight of $4 \mathrm{~kg}$ originally obtained.
\end{abstract}

Keywords: Investment Casting, ceramic shell recycling, waste reduction. 


\section{INTRODUÇÃO}

A microfusão, também conhecida como fundição de precisão ou fundição por cera perdida, é um processo utilizado para a produção de peças com variações ou tolerâncias dimensionais restritas, de tal forma que após a fundição as peças necessitam de pouco acabamento. Este processo é descrito na literatura (Stefanescu, 2002; Hitchiner Manufacturing, 2000; Sopcak, 1986; Prasad, 2013).

O chamote (Mineração Curimbaba, 2008) é uma das matérias-primas consumidas para a constituição da casca cerâmica, utilizada no processo de microfusão, sendo descartado após sua utilização. O descarte produz custos para a empresa, pois este resíduo é encaminhado para um aterro. De acordo com Holtzer et al. (2010) mais de $60 \%$ dos resíduos da microfusão são constituídos por casca cerâmica.

Este trabalho de reciclagem da casca cerâmica foi desenvolvido visando a redução do volume de resíduos sólidos destinados à aterros sanitários, e a diminuição da importação de matérias-primas como, por exemplo, o óxido de zircônio, uma das matérias-primas utilizadas na microfusão.

\section{METODOS}

Aproximadamente $4 \mathrm{~kg}$ do resíduo foram coletados no ponto de descarte da casca cerâmica, conforme a Figura 1.

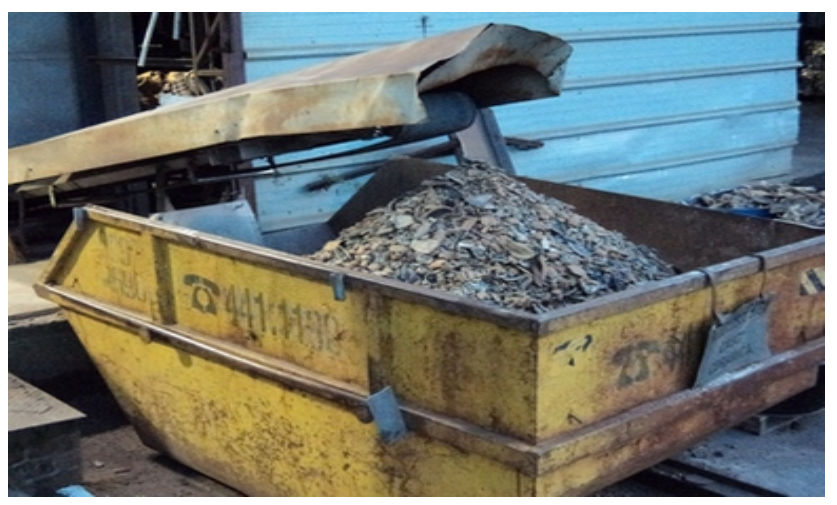

Figura 1. Descarte da casca cerâmica.

Posteriormente, o resíduo foi triturado em um cadinho de aço (Figura 2) manufaturado para esta atividade.

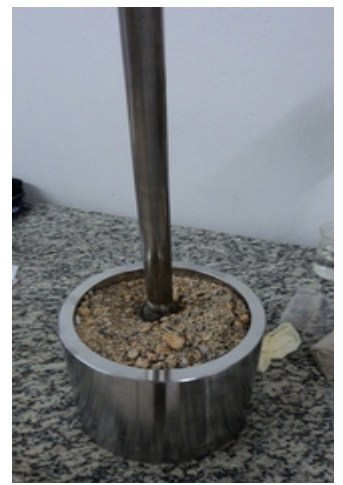

Figura 2. Cadinho confeccionado em aço para a trituração manual da casca cerâmica.

Após a etapa de trituração o resíduo foi peneirado e classificado conforme sua granulometria em peneiras padrão ABNT tamanhos \#18, \#20, \#30, \#40, \#60 e \#80. Efetuou-se a comparação visual entre o chamote reciclado e o chamote virgem em um macroscópio PANTEC, modelo trinocular, para a determinação de diferenças entre os produtos.

O material peneirado foi posteriormente combinado e agrupado de forma a imitar as proporções granulométricas recomendadas pelo fabricante da matéria-prima virgem.

Paralelamente, montou-se um cacho ${ }^{1}$ com peças de formato aleatório, visando analisar se o formato da peça poderia influenciar a resistência da casca cerâmica durante o vazamento do aço.

O cacho, em cera, seguiu para o primeiro recobrimento (com matéria-prima virgem). O objetivo deste banho é a formação de uma camada uniforme, capaz de manter com perfeição a forma do cacho. Realizou-se a aplicação do prime coate (Figura 3) e do banho de areia (Figura 4).
1Cacho é o nome dado a estrutura em cera que serve de molde ao processo de microfusão. 


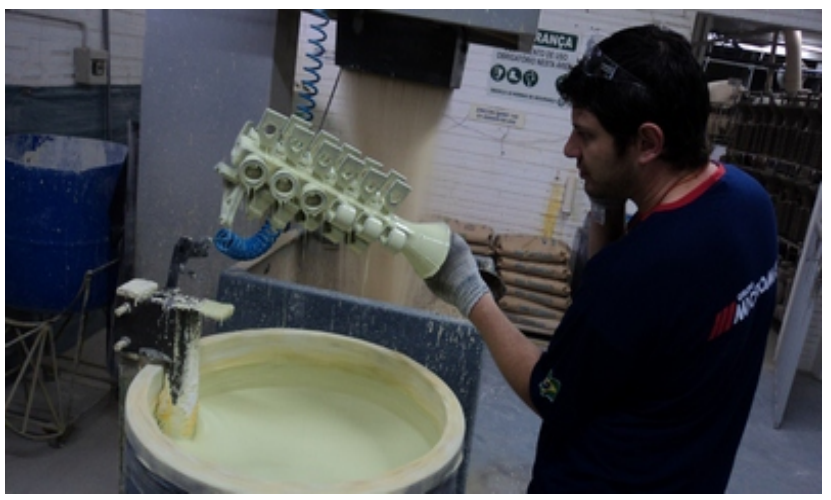

Figura 3. Aplicação do prime coate.

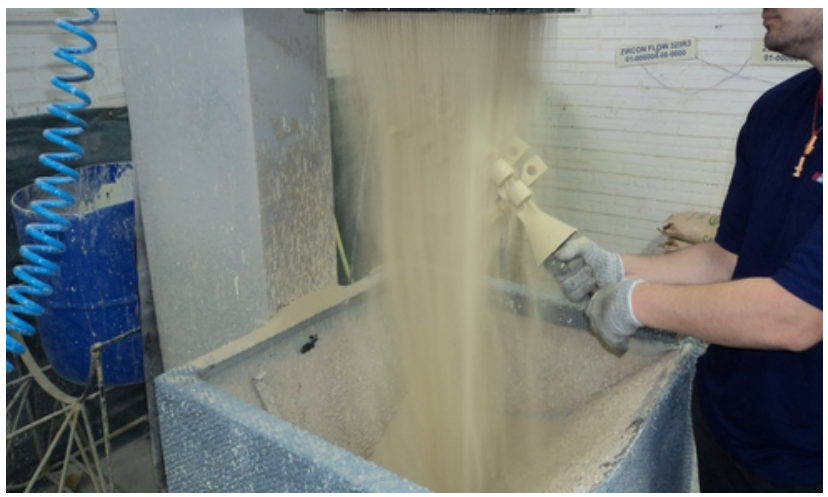

Figura 4. Aplicação da chuva de areia

Após o banho de areia, o cacho ficou em repouso por 6 horas. $O$ cacho seco prosseguiu para o segundo banho de lama (Figura 5).

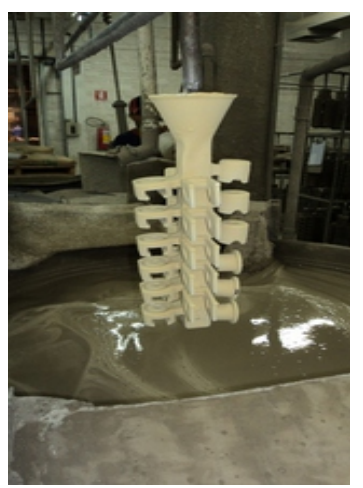

Figura 5. Segundo banho de lama.

Logo após o banho de lama, o cacho recebeu o recobrimento manual do chamote reciclado, previamente preparado, conforme a Figura 6.

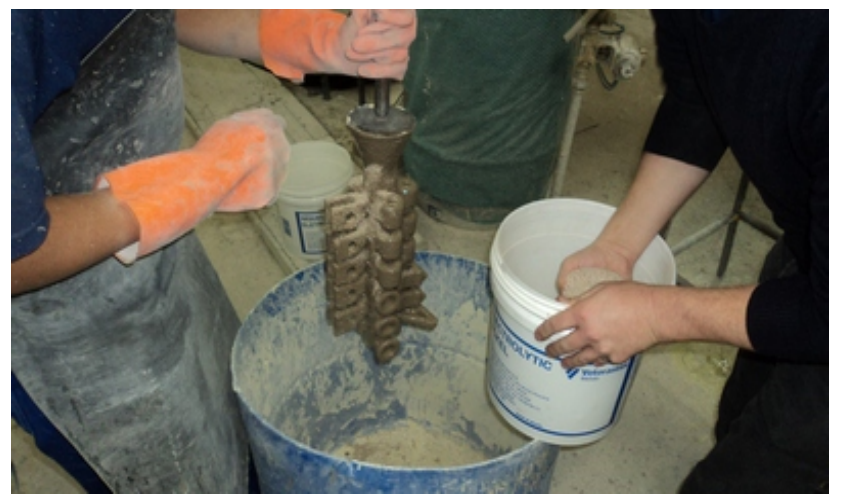

Figura 6. Processo de adição manual do chamote.

Após a aplicação do primeiro banho de lama, o cacho ficou em repouso por 8 horas. Posteriormente, outro banho de lama para encorporação de chamote fino com intervalo de 8 horas e mais três banhos de lama para a adição do chamote grosso. Entre os banhos finais, o intervalo de secagem foi de 8 horas. Em seguida realizou-se o banho de selagem, seguido de repouso de 48 horas para a secagem do cacho. A cera foi removida da casca por aquecimento e pressão e a casca foi calcinada à temperaturas entre 950 e $1100^{\circ} \mathrm{C}$. Após, a casca cerâmica recebeu a adição da liga metálica grau WCB, cuja composição foi posteriormente analisada um aparelho da marca Metec, modelo Spectromaxx.

O aço grau WCB foi vertido no molde, conforme a Figura 7, e posteriormente foi para o martelete, onde a a casca cerâmica é separada do metal já resfriado.

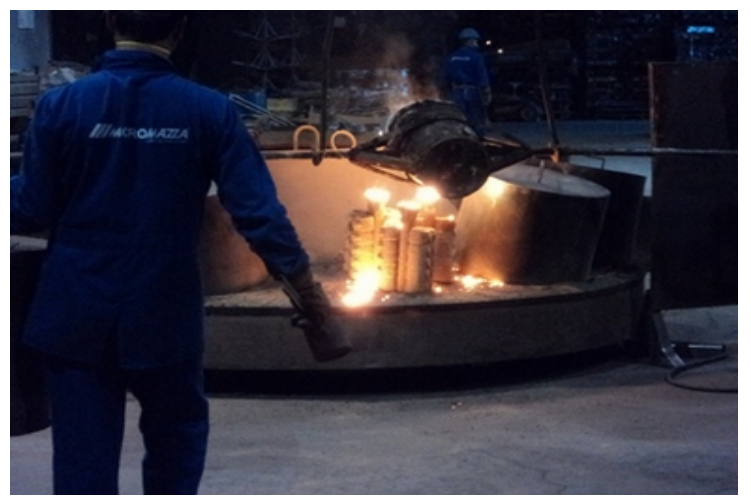

Figura 7. Aço vertido em cascas cerâmicas.

Após a separação das peças microfundidas da casca cerâmica, esta retornou ao seu ponto de coleta, seguindo para o descarte. 


\section{RESULTADOS E DISCUSSÃO}

Optou-se por realizar a quebra da casca cerâmica manualmente, ao invés de utilizar-se um sistema de rolos conforme recomendado por Peters e Twarog (1992), em virtude do tamanho projetado para o experimento. Para ensaios de proporções significativamente maiores que as utilizadas neste trabalho, a utilização de rolos para moer a casca cerâmica deve ser considerada.

A comparação macroscópica entre a casca cerâmica reciclada e a casca cerâmica virgem (Tabela 1 - Figuras 8 a 11) revela a presença de argila aderida à casca cerâmica reciclada. A argila, proveniente do processo do banho de lama, confere ao material reciclado coloração mais escura.

A Tabela 2, apresenta a composição química do aço grau WCB fundido na casca cerâmica, que produziu o cacho da Figura 12.

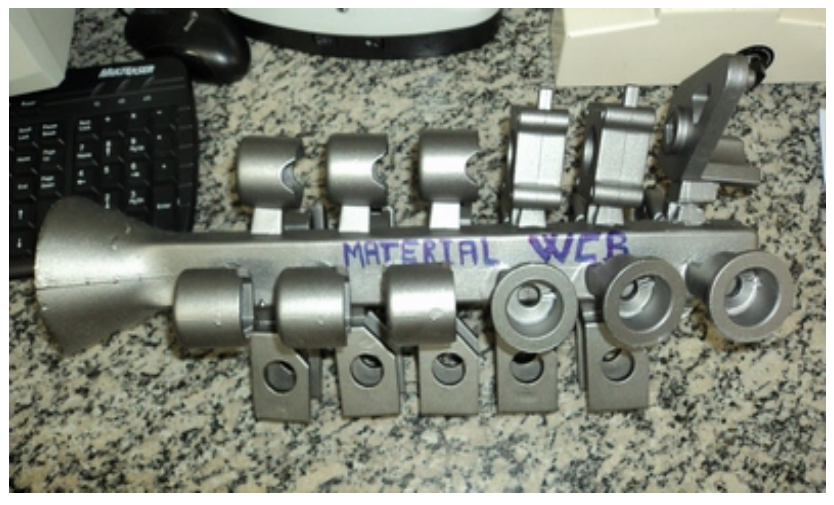

Figura 12. Peças microfundidas em WCB presas ao cacho.

\section{CONCLUSÕES}

Concluiu-se que a casca cerâmica pode ser reciclada e reaproveitada no processo de microfusão, ao menos por uma vez, retornando-a qualidade de matéria-prima. Este processo não comprometeu a qualidade da casca cerâmica reciclada, que apresentou características similares a casca feita com matéria-prima virgem, ou a qualidade das peças do produto microfundido final.

A coloração em tom marrom do chamote reciclado deve-se a presença de argila aderida à sua superfície. No presente experimento esta aparência diferenciada não influenciou as características finais da casca cerâmica, que manteve resistência equivalente a do produto elaborado com matéria-prima virgem.

O processo de reciclagem não substituirá totalmente a aquisição de matéria-prima virgem, observando que, durante a moagem ocorre a quebra dos grãos do chamote e gradualmente a matéria-prima se deteriora em frações diminutas que não servem mais para esta aplicação.

\section{AGRADECIMENTOS:}

Os autores agradecem a Micromazza PMP pelo suporte financeiro e técnico para o desenvolvimento deste trabalho.

\section{REFERÊNCIAS:}

1. ASTM A216 / A216M - 12. Standard Specification for Steel Castings, Carbon, Suitable for Fusion Welding, for HighTemperature Service.

2. Stefanescu, D.M. Asm Handbook: Casting. Vol. 15. Asm International, 2002.

3. Sopcak, J. E. Handbook of Lost Wax or Investment Casting. Gembooks, 1986.

4. Bidwell, H. T. Investment Casting Handbook. Investment Casting institute, 1997.

5. Hitchiner Manufacturing Co., Inc. An Introduction to the Investment Casting Process. 2000. $<$ http://www.hitchiner.com/publications/Intr o_to_IC.pdf>

6. M. Holtzer, J. Zych, R. Dańko, A. Bobrowski. Reclamation of material from used ceramic moulds applied in the investment casting technology. 2010. ARCHIVES of FOUNDRY ENGINEERING Volume 10, Issue 3/2010, 199-204

7. PETERS, T. M.; TWAROG, D. L. The feasibility of reclaming investment shell material from investment castings. 1992. $<$ http://www.w. mrc.uiuc.edu/info/library_docs/tr/tr04.pdf>.

8. PRASAD, Ram. Progress in Investment Castings. Disponível em $<$ http://cdn.intechopen.com/pdfs/39309/ln Tech-Progress_in_investment_castings .pdf>. Acesso em Janeiro, 2013. 
9. Mineração Curimbaba. Argila sinterizada MC-60/ROT-1500. 2008. Disponível em $<$ http://www.curimbaba.com.br/pt/produto s/pdf/mc_60_chamote.pdf>. Acesso em Mar. 2013.

Tabela 1. Comparação macroscópica entre matéria-prima virgem e reciclada.

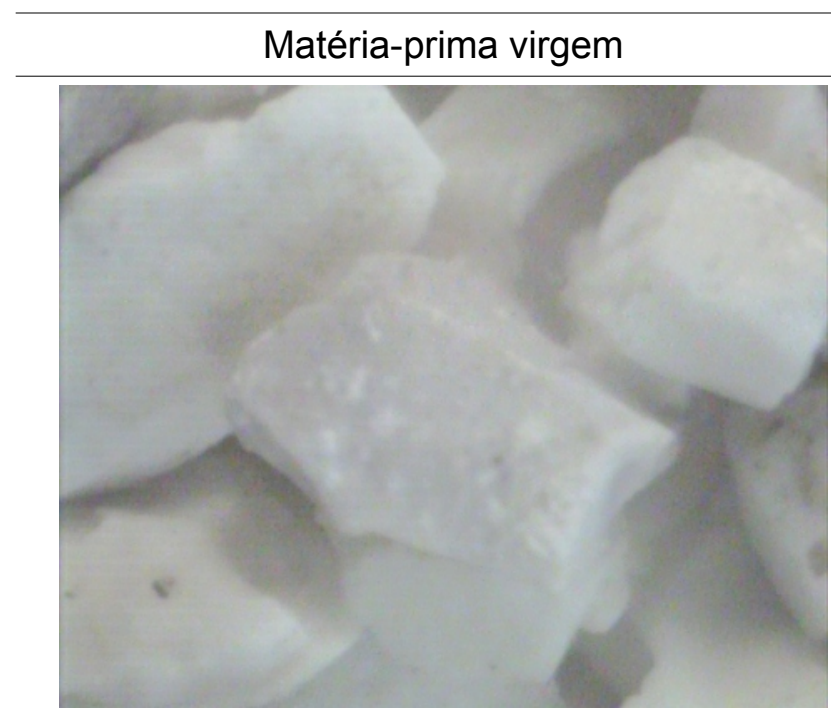

Figura 8. Ampliação 10x

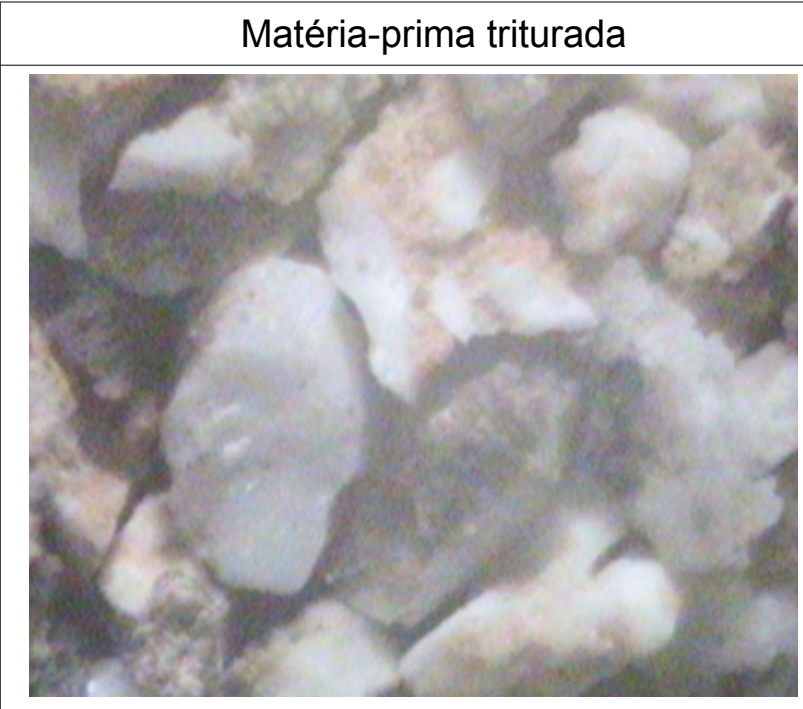

Figura 9. Ampliação 10x

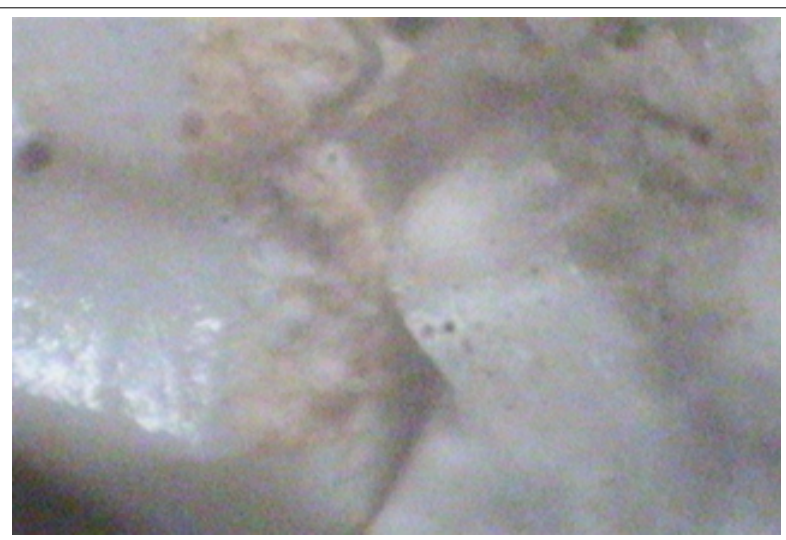

Figura 11. Ampliação 40x.
Figura 10. Ampliação 40x

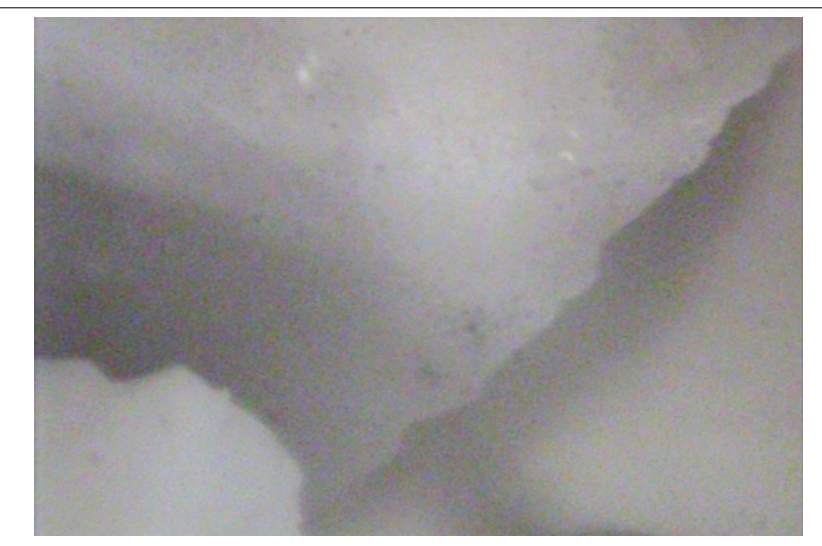

Tabela 2 - Composição química do aço WCB analisado

\begin{tabular}{|c|c|c|c|c|c|c|c|}
\hline C \% & Si \% & Mn \% & P \% & S \% & $\mathrm{Cr} \%$ & Mo \% & $\mathrm{Ni} \%$ \\
\hline 0,226 & 0,227 & 0,974 & 0,024 & 0,010 & 0,083 & 0,012 & 0,044 \\
\hline Al \% & Co \% & $\mathrm{Cu} \%$ & $\mathrm{Nb} \%$ & $\mathrm{Ti} \%$ & V \% & W \% & $\mathrm{Pb} \%$ \\
\hline 0,002 & 0,007 & 0,014 & 0,005 & $<0,0002$ & 0,001 & 0,018 & 0,001 \\
\hline Sn \% & As \% & Zr \% & $\mathrm{Bi} \%$ & $\mathrm{Ca} \%$ & $\mathrm{Ce} \%$ & Sb \% & $\mathrm{Se} \%$ \\
\hline 0,001 & 0,012 & 0,002 & 0,014 & $<0,0001$ & 0,004 & $<0,001$ & 0,002 \\
\hline Ta \% & B \% & $\mathrm{Zn} \%$ & La \% & $\mathrm{N} \%$ & $\mathrm{Fe} \%$ & $\mathrm{Te} \%$ & \\
\hline 0,071 & 0,0005 & 0,003 & $<0,0003$ & 0,025 & 98,3 & 0,001 & \\
\hline
\end{tabular}

PERIÓDICO TCHÊ QUÍMICA • www.periodico.tchequimica.com • Vol. 10 N. 19. - ISSN 1806-0374 (impresso) • ISSN 1806-9827 (CD-ROM) • ISSN 2179-0302 (meio eletrônico)

(C) 2011. Porto Alegre, RS. Brasil

The Periódico Tchê Química (ISSN: 1806-0374; 2179-0302) is an open-access journal since 2004. Journal DOI: 10.52571/PTQ. http://www.tchequimica.com. This text was introduced in this file in 2021 for compliance reasons.

() The Author(s)

OPEN ACCESS. This article is licensed under a Creative Commons Attribution 4.0 (CC BY 4.0) International License, which permits use, sharing, adaptation, distribution, and reproduction in any medium or format, as long as you give appropriate credit to the original author(s) and the source, provide a link to the Creative Commons license, and indicate if changes were made. The images or other third-party material in this article are included in the 